\title{
Spectroscopic Observation of a Hydrogenated CO Dimer Intermediate During CO Reduction on Cu(100) Electrodes
}

\author{
Elena Pérez-Gallent, Marta C. Figueiredo, Federico Calle-Vallejo,* and Marc T. M. Koper*
}

\begin{abstract}
Carbon dioxide and carbon monoxide can be electrochemically reduced to useful products such as ethylene and ethanol on copper electrocatalysts. The process is yet to be optimized and the exact mechanism and the corresponding reaction intermediates are under debate or unknown. In particular, it has been hypothesized that the $C-C$ bond formation proceeds via $\mathrm{CO}$ dimerization and further hydrogenation. Although computational support for this hypothesis exists, direct experimental evidence has been elusive. In this work, we detect a hydrogenated dimer intermediate (OCCOH) using Fourier transform infrared spectroscopy at low overpotentials in LiOH solutions. Density functional theory calculations support our assignment of the observed vibrational bands. The formation of this intermediate is structure sensitive, as it is observed only during $\mathrm{CO}$ reduction on $\mathrm{Cu}(100)$ and not on $\mathrm{Cu}(111)$, in agreement with previous experimental and computational observations.
\end{abstract}

A considerable number of experimental observations as well as density functional theory (DFT) calculations have established that $\mathrm{CO}_{2}$ and $\mathrm{CO}$ reduction on copper electrodes forms $\mathrm{C}_{1}$ and $\mathrm{C}_{2}$ products through different reaction pathways. ${ }^{[1]}$ The formation of $\mathrm{C}_{1}$ and $\mathrm{C}_{2}$ products has been shown to be highly sensitive to copper surface structure and electrolyte $\mathrm{pH}^{[2]}$ Hori et al. ${ }^{[2 \mathrm{a}]}$ have shown that the $\mathrm{CO}$ to $\mathrm{CH}_{4}$ reduction follows a concerted proton-electron transfer mechanism, in stark contrast with $\mathrm{C}_{2} \mathrm{H}_{4}$ production, the rate-limiting step of which is not sensitive to $\mathrm{pH}$ and only involves an electron transfer. As a result, on the $\mathrm{pH}$-corrected RHE reference scale, the formation of ethylene from $\mathrm{CO}$ depends on $\mathrm{pH}$ while that of $\mathrm{CH}_{4}$ does not. ${ }^{[2 \mathrm{a}, \mathrm{c}]}$ Furthermore, Schouten et al. have shown that $\mathrm{C}_{2} \mathrm{H}_{4}$ formation takes place preferentially at $\mathrm{Cu}(100)$ electrodes without simultaneous $\mathrm{CH}_{4}$ formation, which indicates that the reaction paths towards $\mathrm{CH}_{4}$ and $\mathrm{C}_{2} \mathrm{H}_{4}$ must bifurcate in the early stages of $\mathrm{CO}$ reduction. ${ }^{[2 \mathrm{~d}]}$ Specifically, a $\mathrm{C}_{2}$ intermediate that requires only electron transfer, namely a negatively charged $\mathrm{CO}$ dimer, has been proposed as the first $\mathrm{C}-\mathrm{C}$ coupled intermediate. ${ }^{[1 \mathrm{a}, 2 \mathrm{e}, 3]}$ Various recent computational works have studied the structural sensitivity of this intermediate, and concluded that the formation of the dimer is indeed favored both thermodynami-

[**] E. Pérez-Gallent, Dr. M. C. Figueiredo, Dr. F. Calle-Vallejo, Prof. M. T. M. Koper

Leiden Institute of Chemistry, Leiden University PO Box 9502, 2300 RA Leiden (The Netherlands)

E-mail: f.calle.vallejo@chem.leidenuniv.nl m.koper@chem.leidenuniv.nl

Supporting information for this article can be found under: http://dx.doi.org/10.1002/anie.201700580. cally and kinetically on $\mathrm{Cu}(100)$ sites compared to $\mathrm{Cu}$ (111)..$^{[3,4]}$

However, there is still no direct experimental evidence that proves $\mathrm{CO}$ dimerization in aqueous solution during $\mathrm{CO}$ reduction on copper electrodes, and the existence of the dimer is mostly a logical deduction from experimental and computational results. Here, we provide experimental evidence for the formation of a hydrogenated $\mathrm{CO}$ dimer $(\mathrm{OCCOH})$ at low overpotentials during $\mathrm{CO}$ reduction on $\mathrm{Cu}(100)$ electrodes in $\mathrm{LiOH}$ solution, employing in situ Fourier transform infrared spectroscopy (FTIR), and support our interpretation by detailed DFT calculations.

Figure 1 shows the potential-dependent absorbance spectra of $\mathrm{Cu}(100)$ in $0.1 \mathrm{M} \mathrm{LiOH}$ solutions in Argon atmosphere
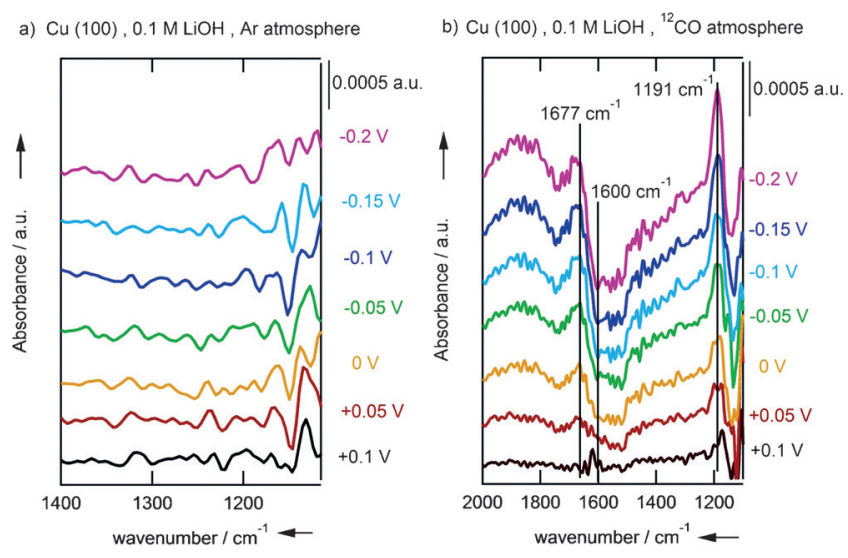

Figure 1. Potential-dependent absorbance spectra for $\mathrm{Cu}(100)$ in the a) absence and b) presence of $\mathrm{CO}$ in a $0.1 \mathrm{~m} \mathrm{LiOH}$ solution. Reference spectrum recorded at $+0.1 \mathrm{~V}$ vs. RHE. Highlighted bands and their corresponding frequencies are indicated with a vertical line at

$1191 \mathrm{~cm}^{-1}$ for ${ }^{12} \mathrm{C}-\mathrm{OH}$ stretching, $1677 \mathrm{~cm}^{-1}$ for ${ }^{12} \mathrm{C}=\mathrm{O}$ stretching and $1600 \mathrm{~cm}^{-1}$ for $\mathrm{O}-\mathrm{H}$ bending.

(Figure 1 a) and in $\mathrm{CO}$ atmosphere (Figure $1 \mathrm{~b}$ ). The reference spectrum is taken at $+0.1 \mathrm{~V}$ and additional spectra are provided for $+0.05,0.00,-0.05,-0.10,-0.15$ and $-0.2 \mathrm{~V}$ (all reported potentials are on the RHE scale). Full range FTIR spectra appear in the Supporting Information (SI), section S2. First of all, in Argon atmosphere the absorption spectra do not display any bands. After $\mathrm{CO}$ is bubbled through the solution, three bands appear at 1677,1600 and $1191 \mathrm{~cm}^{-1}$. The band at $1600 \mathrm{~cm}^{-1}$ corresponds to the $\mathrm{O}-\mathrm{H}$ bending mode of $\mathrm{H}_{2} \mathrm{O}$. This band causes fluctuations in the baseline of the spectra making it difficult to identify other bands in this wavenumber range. The band at $1677 \mathrm{~cm}^{-1}$ corresponds to the $\mathrm{C}=\mathrm{O}$ stretching ${ }^{[5]}$ of $\mathrm{CO}$ adsorbed on hollow sites on $\mathrm{Cu}(100)$, 
in agreement with DFT calculations (see Figure 3 below). The intensity of the band for $\mathrm{CO}$ at multi bonded sites increases with more negative electrode potential. In alkaline media, the absolute potential (on the SHE scale) is more negative compared to acidic conditions and, consequently, the band for $\mathrm{CO}$ at multifold sites dominates the spectra. ${ }^{[6]}$

Simultaneously with the CO-related band, a band at $1191 \mathrm{~cm}^{-1}$ associated with $\mathrm{C}-\mathrm{OH}$ stretching ${ }^{[7]}$ grows in the spectra. Importantly, when $\mathrm{CO}$ reduction was performed under the exact same conditions on a $\mathrm{Cu}(111)$ electrode (see SI, Figure S1), the band at $1191 \mathrm{~cm}^{-1}$ and the band corresponding to $\mathrm{C}=\mathrm{O}$ stretching at $1677 \mathrm{~cm}^{-1}$ were not observed. Figure $1 \mathrm{a}$ shows the absorbance spectra on $\mathrm{Cu}(100)$ without CO. The absence of the band at $1191 \mathrm{~cm}^{-1}$ strongly suggests that the signal appearing in $\mathrm{CO}$ atmosphere comes from a Ccontaining species. In order to ensure that the band at $1191 \mathrm{~cm}^{-1}$ comes from a C-containing species, a spectrum taken with isotopically labeled carbon ${ }^{13} \mathrm{CO}$ was recorded. When the absorbance spectra were obtained in ${ }^{13} \mathrm{CO}$ atmosphere (see Figure 2a), the band shifts from $1191 \mathrm{~cm}^{-1}$ to $1145 \mathrm{~cm}^{-1}$. The shift of approximately $45 \mathrm{~cm}^{-1}$ matches the expected shift for the absorption spectra of ${ }^{13} \mathrm{C}$ compared to ${ }^{12} \mathrm{C},{ }^{[8]}$ confirming that the band at $1191 \mathrm{~cm}^{-1}$ comes from a Ccontaining species.

As mentioned before, water exhibits a wide $\mathrm{O}-\mathrm{H}$ bending band in the $1650-1450 \mathrm{~cm}^{-1}$ range, which prevents the straightforward observation of vibrations from other species in this wavenumber range. For this reason, $\mathrm{CO}$ reduction on $\mathrm{Cu}(100)$ was performed in $\mathrm{D}_{2} \mathrm{O}$; the corresponding spectra are shown in Figure 2 b. In $\mathrm{D}_{2} \mathrm{O}$ electrolyte, the range of 1650 $1450 \mathrm{~cm}^{-1}$ is free of water bands, allowing for the identification of additional bands. Unfortunately, $\mathrm{D}_{2} \mathrm{O}$ has an $\mathrm{O}-\mathrm{D}$ bending band at $1209 \mathrm{~cm}^{-1}$ masking the $\mathrm{C}-\mathrm{OH}$ stretching band. Interestingly, Figure $2 \mathrm{~b}$ shows that in $\mathrm{D}_{2} \mathrm{O}$ electrolyte at $+0.05 \mathrm{~V}$ and more negative potentials a band appears around $1584 \mathrm{~cm}^{-1}$, which corresponds to a $\mathrm{C}=\mathrm{O}$ stretch but is not adsorbed CO.

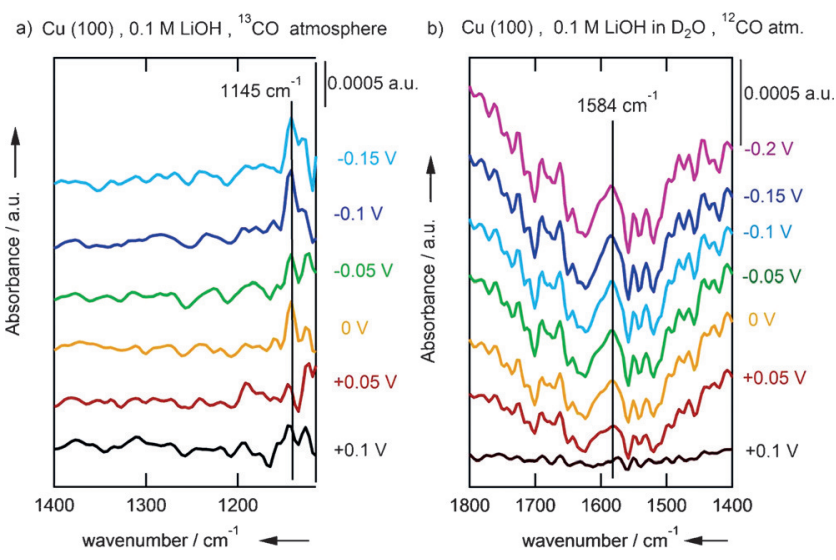

Figure 2. Potential dependent absorbance spectra for $\mathrm{Cu}(100)$ in the presence of a) ${ }^{13} \mathrm{CO}$ and with b) $\mathrm{D}_{2} \mathrm{O}$ as electrolyte in a $0.1 \mathrm{M} \mathrm{LiOH}$ solution. Reference spectrum recorded at $+0.1 \mathrm{~V}$ vs. RHE. Highlighted bands and their corresponding frequencies are indicated with a vertical line at $1145 \mathrm{~cm}^{-1}$ for ${ }^{13} \mathrm{C}-\mathrm{OH}$ stretching and $1584 \mathrm{~cm}^{-1}$ for ${ }^{12} \mathrm{C}=\mathrm{O}$ stretching.
From the combined results of the experiments in $\mathrm{H}_{2} \mathrm{O}$ and $\mathrm{D}_{2} \mathrm{O}$, we observe two vibrational bands coming from Ccontaining species that are formed at low overpotentials on $\mathrm{Cu}(100)$ only. It is important to note that at the low overpotentials considered in our experiments, namely +0.1 to $-0.15 \mathrm{~V}$, no products are observed (for instance, the earliest onset potential on $\mathrm{Cu}(100)$ is that of $\mathrm{C}_{2} \mathrm{H}_{4}$ at $-0.4 \mathrm{~V}) .{ }^{[2 \mathrm{~d}, 9]}$ Thus, the bands in question should, in principle, be assigned to vibrations of adsorbed intermediates of $\mathrm{CO}$ reduction rather than to species in solution. To verify this hypothesis, we have scrutinized the IR spectra of various possible species in solution, including various $\mathrm{C}_{1}$ and $\mathrm{C}_{2}$ species.

Transmission spectra of species in solution such as formaldehyde, formate and methanol $\left(\mathrm{C}_{1}\right.$ molecules $)$, and acetaldehyde and acetic acid $\left(\mathrm{C}_{2}\right.$ molecules $)$ were recorded and are shown in Figure S2. The absence of the bands at 1191 and $1584 \mathrm{~cm}^{-1}$ in the transmission spectra rules out the possibility that the bands observed during the reduction of $\mathrm{CO}$ on $\mathrm{Cu}(100)$ correspond to these species in solution. Although methanol has a $\mathrm{C}-\mathrm{OH}$ vibration at $1195 \mathrm{~cm}^{-1}$ in $0.1 \mathrm{M} \mathrm{LiOH}$, the vibration at $1584 \mathrm{~cm}^{-1}$ is absent (see SI, Figure S2c) and its substantially negative onset potential $\left(-0.95 \mathrm{~V}^{[1 \mathrm{~d}]}\right)$ precludes the presence of methanol at the low overpotentials at which this work was performed $(+0.1$ to $-0.15 \mathrm{~V})$. The transmission spectra of acetaldehyde also displays a band at $1195 \mathrm{~cm}^{-1}$, however, this band is associated with the $\mathrm{C}-\mathrm{OH}$ stretching from the methanol present in the acetaldehyde solution as a stabilizer. In addition, acetaldehyde presents other two bands at 1712 and $1666 \mathrm{~cm}^{-1}$. The absence of these bands in the spectra obtained during $\mathrm{CO}$ reduction rules out the possibility of acetaldehyde as a product. Another compound that could have vibrational frequencies close to those in Figure 1 and Figure 2 is acetylenediol $(\mathrm{HOC} \equiv \mathrm{COH})$. Maier et al. collected the infrared spectra of this double alcohol ${ }^{[10]}$ and reported a single $\mathrm{C}-\mathrm{OH}$ stretching band at $1212 \mathrm{~cm}^{-1}$.

Having verified that the observed bands at 1191 and $1584 \mathrm{~cm}^{-1}$ do not correspond to species in solution, we now resort to DFT calculations to see whether a given adsorbed intermediate or a combination of them exhibit such bands. Since both $\mathrm{CH}_{4}$ and $\mathrm{C}_{2} \mathrm{H}_{4}$ production from $\mathrm{CO}$ possess relatively early rate-limiting steps, ${ }^{[1,11]}$ we have limited our analysis to $\mathrm{C}_{1}$ and $\mathrm{C}_{2}$ species with no or a low content of hydrogen atoms (see Figure 3 ). First, consider the $\mathrm{C}_{1}$ species $\mathrm{CHO}$ and $\mathrm{COH}$ (Figure $3 \mathrm{~b}, \mathrm{c}$ ), which are the two possible products of the first hydrogenation of $\mathrm{CO}$. They both have bands close to the band observed during the adsorption/ reduction of ${ }^{12} \mathrm{CO}$ on $\mathrm{Cu}(100)$ at $1191 \mathrm{~cm}^{-1}$ (Figure $1 \mathrm{~b}$ ), but none of them exhibit the additional vibrational band at $1584 \mathrm{~cm}^{-1}$ (Figure 2b). Based on the experimental and DFTcalculated onset potential for $\mathrm{CH}_{4}$ production on $\mathrm{Cu}(100)$ $(\approx-0.8 \mathrm{~V})$, and bearing in mind that $\mathrm{CO}$ protonation is deemed the potential-determining step of $\mathrm{CO}_{2} / \mathrm{CO}$ reduction to $\mathrm{CH}_{4},{ }^{[12]}$ we do not expect $\mathrm{COH}$ or $\mathrm{CHO}$ to be present at the low potentials at which our experiments were performed. The CO dimer (OCCO, Figure 3d) also presents a vibrational band at $1200 \mathrm{~cm}^{-1}$ but does not exhibit a band around $1584 \mathrm{~cm}^{-1}$. Besides, a lithiated dimer (Figure $3 \mathrm{e}$ ) features two 
a) $\mathrm{CO}$

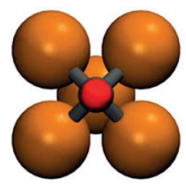

$1714 \mathrm{~cm}^{-1}$ b)

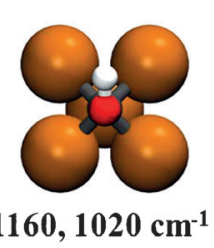

c) $\mathrm{CHO}$

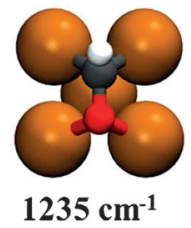

d) $\mathrm{OCCO}$ (I)

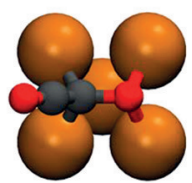

$1200 \mathrm{~cm}^{-1}$ e) $\mathrm{OCCO}$ (II)

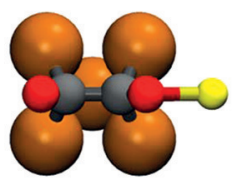

$1486,1376 \mathrm{~cm}^{-1}$

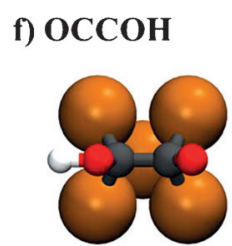

$1576,1235 \mathrm{~cm}^{-1}$ g) $\mathrm{OCCHO}$

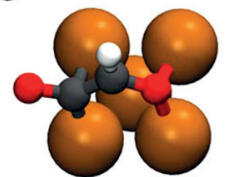

$1313,1200,1071 \mathrm{~cm}^{-1}$ h) $\mathrm{HOCCOH}$

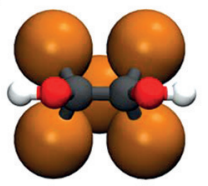

$1397,1229,1150 \mathrm{~cm}^{-1}$
Figure 3. Schematic structures of possible adsorbed intermediates on $\mathrm{Cu}(100)$ and their calculated infrared-active vibrational frequencies in the $1100-1600 \mathrm{~cm}^{-1}$ wavenumber region. $\mathrm{Cu}, \mathrm{Li}, \mathrm{C}, \mathrm{O}$, and $\mathrm{H}$ atoms are depicted as orange, yellow, gray, red and white spheres.

C-O stretching frequencies that are not close to either of the bands at 1191 and $1584 \mathrm{~cm}^{-1}$. Conversely, a CO dimer in which one of the oxygen atoms has been hydrogenated ( $\mathrm{OCCOH}$, Figure $3 \mathrm{f})$ exhibits bands close to both experimental bands. In addition, we have calculated the vibrational signatures of a $\mathrm{CO}$ dimer of which one of the carbon atoms has been hydrogenated (OCCHO, Figure $3 \mathrm{~g}$ ). This adsorbate has vibrational bands around 1313,1200, and $1071 \mathrm{~cm}^{-1}$ but no band close to $1584 \mathrm{~cm}^{-1}$. Adsorbed acetylenediol, namely a doubly hydrogenated $\mathrm{CO}$ dimer $(\mathrm{HOCCOH}$, Figure $3 \mathrm{~h})$ was also considered in our DFT calculations. The predicted vibrational frequencies for $\mathrm{C}-\mathrm{OH}$ stretching are 1397, 1229 and $1150 \mathrm{~cm}^{-1}$. We also considered a simultaneously hydrogenated and lithiated dimer (HOCCOLi) and its vibrational frequencies were found at 1427 and $1246 \mathrm{~cm}^{-1}$. Finally, a doubly lithiated dimer ( $\mathrm{LiOCCOLi})$ possesses $\mathrm{C}=\mathrm{O}$ stretching frequencies at 1329 and $1261 \mathrm{~cm}^{-1}$.

Therefore, we conclude that the bands at 1191 and $1584 \mathrm{~cm}^{-1}$ arise from $\mathrm{C}-\mathrm{O}-\mathrm{H}$ and $\mathrm{C}-\mathrm{O}$ stretching vibrations and correspond, in the simplest case, to a hydrogenated dimer $(\mathrm{OCCOH})$, or in general to this adsorbate in combination with other $\mathrm{C}_{1}$ and $\mathrm{C}_{2}$ adsorbates. This is in line with previous computational works showing that $\mathrm{OCCOH}$ is the most stable intermediate formed after the first hydrogenation of $\mathrm{CO}$ on $\mathrm{Cu}(100) .^{[3]}$

In conclusion, we have shown experimentally that $\mathrm{Cu}$ (100) electrodes in $\mathrm{LiOH}$ solutions host a C-containing adsorbate at low overpotentials with vibrational bands at 1191 and $1584 \mathrm{~cm}^{-1}$. Based on DFT calculations of a wide variety of $\mathrm{C}_{1}$ and $\mathrm{C}_{2}$ intermediates, we ascribe these bands to the $\mathrm{C}-\mathrm{O}-\mathrm{H}$ and $\mathrm{C}=\mathrm{O}$ stretching modes of a hydrogenated $\mathrm{CO}$ dimer $(\mathrm{OCCOH})$. These results provide for the first time direct confirmation of an important hypothesis in the electrocatalysis of $\mathrm{CO}_{2}$ reduction on copper, namely that the $\mathrm{C}-\mathrm{C}$ coupling to $\mathrm{C}_{2}$ species on $\mathrm{Cu}(100)$ takes place through a reductive dimerization step at the early stages of the reaction mechanism. The fact that the vibrational features ascribed to the $\mathrm{CO}$ dimer could not be observed on $\mathrm{Cu}(111)$ under identical conditions confirms that $\mathrm{CO}$ dimerization is a structure-sensitive process favored by sites with square symmetry, in agreement with previous experimental ${ }^{[2 f]}$ and theoretical studies. ${ }^{[4 b]}$ We are currently performing further experiments and calculations to examine the influence of various alkaline cations on $\mathrm{CO}$ dimerization and their impact on the $\mathrm{CO}$ reduction pathway.

\section{Experimental Section}

Prior to each electrochemical experiment, the glassware used was stored overnight in a solution of $\mathrm{KMnO}_{4}$ that was rinsed with a mixture of ultra clean water (Millipore MilliQ, resistivity $>18.2 \mathrm{M} \Omega$ ), $20 \mathrm{mLL}^{-1}$ of hydrogen peroxide and $1 \mathrm{mLL}^{-1}$ of concentrated sulfuric acid. The glassware was further cleaned by boiling 4 times in Millipore MilliQ water. A coiled platinum wire was used as counter electrode and a reversible hydrogen electrode (RHE) in the same electrolyte was used as reference electrode.

The copper electrodes used were $99.99 \%$ copper disks with a diameter of $6 \mathrm{~mm}$, purchased from Mateck and aligned to $<0.5^{\circ}$ accuracy. Prior to every experiment, the electrodes were electropolished and characterized as described elsewhere. ${ }^{[2 b]}$ Additional details appear in the SI, section S2.

The electrolytes were made from ultra-pure water (Millipore MilliQ, resistivity $>18.2 \mathrm{M} \Omega$ ) and high purity reagents (Sigma Aldrich TraceSelect). Before every experiment, Argon (Linde, 6.0) or CO (Linde 6.0) were bubbled through the electrolyte for 15 minutes in order to remove air from the solution or saturate the solution with $\mathrm{CO}$, and during the experiments the corresponding gas was kept flowing above the solution.

FTIR measurements were performed with a Bruker Vertex $80 \mathrm{~V}$ Infrared spectrophotometer. ${ }^{[13]}$ The electrochemical cell was assembled on top of a $60^{\circ} \mathrm{CaF}_{2}$ prism, and the electrode was situated against this prism to form a thin layer. The measurements were performed under external reflection. FTIR spectra were obtained from an average of 100 scans with a resolution of $8 \mathrm{~cm}^{-1}$ at the selected potentials. Every spectrum was obtained by applying single potential steps compared to the reference potential $(+0.1 \mathrm{~V})$. The spectra are shown as $\left(R-R_{0}\right) / R_{0}$ where $R$ is the reflectance at the sample potential and $R_{0}$ is the reflectance at the reference potential. Thereby the ratio $\Delta R / R_{0}$ gives positive bands for the formation of species at the sample potential, while negative bands correspond to the loss of species at the sample potential. P-polarized light was used to probe species both near the electrode surface and in solution.

The vibrational frequencies were calculated by means of DFT calculations using the VASP code ${ }^{[14]}$ with the PBE exchangecorrelation functional ${ }^{[15]}$ and the projector augmented wave (PAW) method. ${ }^{[16]}$ The $\mathrm{Cu}(100)$ surfaces were modeled with $(3 \times 2)$ 4-layerthick slabs. The vertical separation between periodically repeated images was more than $16 \AA$ and dipole corrections were applied. The structures were optimized allowing the adsorbates and the two topmost layers to relax in all directions, while fixing the 2 bottom layers at the optimized bulk positions. The relaxations were carried out with a plane-wave cut-off of $450 \mathrm{eV}$, using the conjugate-gradient Scheme until the maximum force on any atom was below $0.05 \mathrm{eV} \AA^{-1}$. The Brillouin zones were sampled with $6 \times 8 \times 1$ Monkhorst-Pack meshes. ${ }^{[17]}$ The Fermi level of the surfaces was smeared using the 
Methfessel-Paxton method ${ }^{[18]}$ with $k_{\mathrm{B}} T=0.2 \mathrm{eV}$, and all energies were extrapolated to $0 \mathrm{~K}$.

The vibrational frequency analysis was made using the harmonic oscillator approximation with two displacements in each direction plus the ground state.

\section{Acknowledgements}

F.C.V. acknowledges funding from the Netherlands Organization for Scientific Research (NWO), Veni project number 722.014.009. The use of supercomputing facilities at SURFsara was sponsored by NWO Physical Sciences, with financial support by NWO.

\section{Conflict of interest}

The authors declare no conflict of interest.

Keywords: CO dimer . CO reduction - DFT calculations . electrocatalysis $\cdot$ IR spectroscopy

How to cite: Angew. Chem. Int. Ed. 2017, 56, 3621-3624 Angew. Chem. 2017, 129, 3675-3678

[1] a) M. Gattrell, N. Gupta, A. Co, J. Electroanal. Chem. 2006, 594 1-19; b) Y. Hori, I. Takahashi, O. Koga, N. Hoshi, J. Phys. Chem. $B$ 2002, 106, 15-17; c) A. A. Peterson, F. Abild-Pedersen, F. Studt, J. Rossmeisl, J. K. Nørskov, Energy Environ. Sci. 2010, 3, 1311-1315; d) K. P. Kuhl, E. R. Cave, D. N. Abram, T. F. Jaramillo, Energy Environ. Sci. 2012, 5, 7050-7059; e) R. Kortlever, J. Shen, K. J. P. Schouten, F. Calle-Vallejo, M. T. M. Koper, J. Phys. Chem. Lett. 2015, 6, 4073-4082.

[2] a) Y. Hori, R. Takahashi, Y. Yoshinami, A. Murata, J. Phys Chem. B 1997, 101, 7075-7081; b) K. J. P. Schouten, E. P. Gallent, M. T. M Koper, J. Electroanal. Chem. 2013, 699, 6-9; c) K. J. P. Schouten, E. P. Gallent, M. T. M. Koper, J. Electroanal. Chem. 2014, 716, 53-57; d) K. J. P. Schouten, Z. Qin, E. P. Gallent, M. T. M. Koper, J. Am. Chem. Soc. 2012, 134, $9864-$ 9867; e) K. J. P. Schouten, Y. Kwon, C. J. M. Van der Ham, Z.
Qin, M. T. M. Koper, Chem. Sci. 2011, 2, $1902-1909$; f) K. J. P. Schouten, E. Pérez Gallent, M. T. M. Koper, ACS Catal. 2013, 3, $1292-1295$; g) I. Ledezma-Yanez, E. Perez-Gallent, M. T. M. Koper, F. Calle-Vallejo, Catal. Today 2016, 262, 90-94.

[3] F. Calle-Vallejo, M. T. M. Koper, Angew. Chem. Int. Ed. 2013, 52, 7282-7285; Angew. Chem. 2013, 125, 7423-7426.

[4] a) J. H. Montoya, C. Shi, K. Chan, J. K. Nørskov, J. Phys. Chem. Lett. 2015, 6, 2032-2037; b) H. Li, Y. Li, M. T. M. Koper, F. Calle-Vallejo, J. Am. Chem. Soc. 2014, 136, 15694-15701.

[5] a) Y. Hori, O. Koga, Y. Watanabe, T. Matsuo, Electrochim. Acta 1998, 44, 1389-1395; b) R. Ryberg, Surf. Sci. 1982, 114, $627-$ 641; c) M. Gajdoš, J. Hafner, Surf. Sci. 2005, 590, 117-126.

[6] a) S. C. Chang, M. J. Weaver, J. Phys. Chem. 1990, 94, 50955102; b) R. M. Arán-Ais, M. C. Figueiredo, F. J. Vidal-Iglesias, V. Climent, E. Herrero, J. M. Feliu, Electrochim. Acta 2011, 58, 184-192; c) S. K. Shaw, A. Berná, J. M. Feliu, R. J. Nichols, T. Jacob, D. J. Schiffrin, Phys. Chem. Chem. Phys. 2011, 13, $5242-$ 5251; d) M. T. M. Koper, R. A. van Santen, J. Electroanal. Chem. 1999, $476,64-70$

[7] G. Socrates, Infrared and Raman Characteristic Group Frequencies: Tables and Charts, Wiley, Hoboken, 2004.

[8] M. W. Severson, C. Stuhlmann, I. Villegas, M. J. Weaver, J. Chem. Phys. 1995, 103, 9832-9843.

[9] F. Calle-Vallejo, J. Ignacio Martinez, J. Rossmeisl, Phys. Chem. Chem. Phys. 2011, 13, 15639-15643.

[10] G. Maier, C. Rohr, Liebigs Ann. 1996, 307-309.

[11] a) F. Calle-Vallejo, J. I. Martínez, J. M. García-Lastra, E. Abad, M. T. M. Koper, Surf. Sci. 2013, 607, 47-53; b) X. Nie, M. R. Esopi, M. J. Janik, A. Asthagiri, Angew. Chem. Int. Ed. 2013, 52, 2459-2462; Angew. Chem. 2013, 125, 2519-2522.

[12] W. J. Durand, A. A. Peterson, F. Studt, F. Abild-Pedersen, J. K. Nørskov, Surf. Sci. 2011, 605, 1354-1359.

[13] G. García, P. Rodríguez, V. Rosca, M. T. M. Koper, Langmuir 2009, $25,13661-13666$

[14] G. Kresse, J. Furthmüller, Phys. Rev. B 1996, 54, 11169-11186.

[15] J. P. Perdew, K. Burke, M. Ernzerhof, Phys. Rev. Lett. 1996, 77, $3865-3868$.

[16] G. Kresse, D. Joubert, Phys. Rev. B 1999, 59, 1758-1775.

[17] H. J. Monkhorst, J. D. Pack, Phys. Rev. B 1976, 13, 5188-5192.

[18] M. Methfessel, A. T. Paxton, Phys. Rev. B 1989, 40, 3616-3621.

Manuscript received: January 17, 2017

Final Article published: February 23, 2017 